\title{
Comment
}

Neuroepidemiology 2011;37:141-142

DOI: $10.1159 / 000332609$

\section{Importance of Case Definition in Epidemiological Studies}

Sushil K. Sharma

Center for Science, Technology, and Engineering, Applied Research and Methods, US Government Accountability Office, Washington, D.C., USA

During the 1991 Persian Gulf War, US troops were exposed to a variety of potentially hazardous substances. Shortly after the war, some veterans began reporting a wide array of health problems and disabling conditions, which they believed might be due to exposure to chemicals, pesticides and other hazardous substances used during the war. Consequently, beginning in 1994, federal research on Gulf War illnesses primarily involved retrospective epidemiological studies. Most of these studies focused on the nature and prevalence of the veterans' symptoms and illnesses or the identification of causes of the illnesses. But these studies began without any case definition of particular syndromes or clusters of symptoms.

The use of case definitions is important in retrospective epidemiological studies. Specific standardized criteria for the identification of cases should be established so that there is no ambiguity about types of cases and stages of disease to be included or excluded from a study [1]. In 1994, an NIH panel - recognizing that a single case definition may not be sufficient since there may be more than one disease category - recommended the need for case definition [2].

In 1997, a GAO (Government Accountability Office) study concluded: 'While mortality information and data on the prevalence of various problems may be valuable, because of formidable methodological problems facing investigators, epidemiological research on Gulf War veterans' illnesses will not be able to provide precise, accurate, and conclusive answers regarding the causes of veterans' illnesses' [3].

Further, the GAO study stated that case definition is essential to conducting retrospective epidemiological studies. The specificity of a definition is important because a vague definition can lead to considering multiple kinds of illness together. When a case definition is used, it is not surprising to find no commonality of experience among the cases. Moreover, specificity in case definition is critical to achieving meaningful results within retrospective epidemiological studies. In addition, specific diagnostic criteria are essential to (1) reliably determine who has the disease or condition being studied and (2) select appropriate controls (people who do not have the disease or condition). To the extent that individuals are misclassified as to disease or exposure, conclusions would be misleading and relationships would be obscured.

In 1997, Haley et al. [4-6], in order to arrive at a case definition, focused on identifying symptom clusters. This study tested the hypothesis that the ill-defined symptoms experienced by Gulf War veterans may be due, in part, to organophosphate-induced delayed neuropathy. And this study, by statistical factor analysis, (1) clarified the patterns among veterans' symptoms and (2) demonstrated that vague symptoms displayed by the ill veterans were associated with objective brain and nerve damage compatible with the known chronic effects of exposures to low levels of organophosphates [4-6]. In addition, this study linked the veterans' illnesses to exposure to combinations of chemicals, including nerve agents, pesticides in flea collars, $\mathrm{N}, \mathrm{N}$-diethyl- $m$-toluamide in highly concentrated insect repellents, and pyridostigmine bromide tablets. Finally, this study is a valuable example of an attempt - in the presence of diffuse and nonspecific symptoms - to refine a case definition. However, one limitation of this study was its small sample size.

It is important, therefore, to estimate the size of the sample that would be required to have a reasonable expectation of detecting differences between deployed and nondeployed veterans or exposures to hazardous substances. Many variables are involved in such calculations, for example, the size of the investigated exposure's expected impact on health (consistent lethal effects can be detected in a smaller sample rather than more subtle problems) and the prevalence of exposure, some of which were unknown at the time federal studies were planned, including the study by $\mathrm{Ha}-$ ley et al. [4-6]. Thus, these variables had to be estimated within somewhat broad parameters. Although steps were clearly taken to plan for an adequate sample size, some investigators reported difficulty in locating subjects due to factors beyond their control such as (1) the rate of referrals from Veterans Administration examination centers or (2) the identification of subjects who fit highly specific case definitions.

In the current study, Iannacchione et al. [7] - using a statistically valid sample size and stratified probability sample $(\mathrm{n}=$ 8,020) - replicated Haley's 1997 study [4-6]. The study by Iannacchione et al. [7] demonstrated the usefulness of the case definition of Gulf War illnesses, derived from factor analysis. In testing the external validity of the case definition, the sample size as well as the structural equation modeling were critical factors. In the absence of a case definition, the value of federal studies is questionable. This study by Iannacchione et al. [7], thus, provides a case definition that is empirically derived. It should, therefore, be a valuable resource for future studies.

\section{KARGER}

Fax +41613061234 E-Mail karger@karger.ch www.karger.com
(2) 2011 S. Karger AG, Basel

0251-5350/11/0372-0141\$38.00/0 


\section{References}

1 Mausner JM, Kramer S: Epidemiology. An Introductory Text, ed 2. Philadelphia, Saunders, 1985.

2 The Persian Gulf experience and health. Bethesda, NIH Technol Assess Statement, 1994

3 GAO: Gulf War illnesses: improved monitoring of clinical progress and reexamination of research emphasis are needed. GAO/NSIAD-97-108. Washington, GAO, 1997.

4 Haley RW, Kurt TL, Hom J: Is there a Gulf War syndrome? Searching for syndromes by factor analysis of symptoms. JAMA 1997;277:215222.

5 Haley RW, Hom J, Roland PS, Bryan WW, van Ness PC, Bonte FJ, Devous MD Sr, Mathews D, Fleckenstein JL, Wians FH Jr, Wolfe GI, Kurt TL: Evaluation of neurologic function in Gulf War veterans: a blinded case-control study. JAMA 1997;277:223-230.
6 Haley RW, Kurt TL: Self-reported exposure to neurotoxic chemical combinations in the Gulf War: a cross-sectional epidemiologic study. JAMA 1997;277:231-237.

7 Iannacchione VG, Dever JA, Bann CM, Considine KA, Creel D, Carson $\mathrm{CP}$, Best H, Haley RW: Validation of a research case definition of Gulf War illness in the 1991 US military population. Neuroepidemiology 2011;37:129-140.

Sushil Sharma, PhD, DrPH

Center for Science, Technology, and Engineering

Applied Research and Methods

U.S. Government Accountability Office

441 G Street, NW, Washington, DC 20548 (USA)

Tel. +1 202512 3460, E-Mail sharmas@gao.gov 